Dalby, A. \& Holdsworth, E. (1956). J. gen. Microbiol. 15, 335-344

\title{
Growth Factors for Corynebacterium diphtheriae Strain Dundee
}

\author{
By A. DALBY and E. HOLDSWORTH \\ Department of Biochemistry, University of Leeds
}

\begin{abstract}
SUMMARY: Investigations were continued on the nature of the growth factor requirements of Corynebacterium diphtheriae gravis, strain Dundee. Hypoxanthine, or adenine + guanine, or adenine + xanthine, were found capable of replacing concentrates of the growth factor from liver and yeast.

Nucleoside and nucleotide fractions, prepared from electrophoretically-purified ribonucleic acid, were unable to replace the free purine bases. A purine extract was obtained from an active fish-liver concentrate by copper precipitation. In this extract, a large amount of hypoxanthine and a smaller amount of xanthine were found by chromatography to be the major purine constituents; traces of adenine and guanine were also detected. Chromatographic fractionation and spectrophotometric examination of the fractions confirmed the presence of hypoxanthine and xanthine, whose concentrations were estimated.

The purine extract supported less growth than the original fish-liver concentrates. Growth on the purine extract could be reproduced by a mixture of hypoxanthine and xanthine at an equivalent concentration
\end{abstract}

The work of Mueller, Klise, Porter \& Graybiel (1933) was the starting-point for the study of the nutrition of Corynebacterium diphtheriae. They substituted an acid hydrolysate of casein and tryptophan for commercial peptone and produced a basal medium which with slight modification has been used by subsequent workers in this field. Mueller \& SubbaRow (1937) showed that there were at least two substances present in certain components of liver or meat extracts which were growth accessories for these organisms and later in the same year Mueller $(1937 a, b)$ identified the one as pimelic acid and separated the other fraction into two parts, one of which was identified as nicotinic acid whilst the other was shown to be $\beta$-alanine. Mueller \& Klotz (1938) found that pantothenic acid could replace $\beta$-alanine for their test strain, whilst Evans, Handley \& Happold (1939) showed that pantothenic acid was a growth requirement for certain gravis strains.

Pappenheimer (1936) produced potent diphtheria toxin on a simple amino acid medium which was based on that of Mueller and then in conjunction with Johnson (1936) demonstrated the significance of iron in toxin production.

Chattaway, Happold \& Sandford (1944) and Chattaway, Dolby, Hall \& Happold (1949) reported the presence in liver and yeast concentrates of a factor or factors essential for the growth of certain intermediate and gravis strains of Corynebacterium diphtheriae on an otherwise chemically defined medium. Working with acid hydrolysates of brewers' yeast they obtained chromatographic data which suggested that the active material was associated with four ninhydrin-reacting substances. Two of these were resistant to acid 
hydrolysis and the remaining two appeared to be peptides; these substances were not then fully characterized. The present work was begun with a view to elucidating further the nature of the active material. It was found that hypoxanthine, and certain mixtures of other purines, were able to replace the growth-promoting ability of a fish liver concentrate of active material and the presence of purines was demonstrated in this concentrate.

\section{METHODS}

Organism. The test organism was a strain of Corynebacterium diphtheriae gravis, Dundee subtype, and was the organism used previously by Chattaway et al. (1949).

Inoculum. The organism was maintained on nutrient agar and before testing was subcultured daily for several days on nutrient broth and finally for $24 \mathrm{hr}$. on fresh blood agar at $37^{\circ}$. Sufficient isolated colonies were transferred to $5 \mathrm{ml}$. basal medium to produce a faint turbidity beneath the surface. The organisms were dispersed on a lateral shaker for $5 \mathrm{~min}$. and c. $0.05 \mathrm{ml}$. used per 5 or $10 \mathrm{ml}$. basal medium.

Conditions and assay of growth. Two methods were employed: (i) For routine examinations, growth tests were performed in duplicate $6 \times \frac{5}{8}$ in. test-tubes containing $5 \mathrm{ml}$. medium. After inoculation the tubes were incubated at $37^{\circ}$ for $72 \mathrm{hr}$. and growth was estimated, from the size and thickness of the pellicle formed, by the method of Chattaway et al. (1949). The extent of growth is expressed numerically as a percentage of the growth produced on a standard medium containing the active factor. (ii) When strict quantitative comparison of growth was desired, growth experiments were performed in $50 \mathrm{ml}$. Erlenmeyer flasks containing $10 \mathrm{ml}$. of medium and covered by $30 \mathrm{ml}$. beakers. The flasks were incubated for $144 \mathrm{hr}$. at $37^{\circ}$, the contents transferred to $6 \times 1$ in. Pyrex boiling tubes and centrifuged. The organisms were washed twice with $0.9 \%(w / v)$ saline, once with distilled water and total nitrogen was determined by the micro-Kjeldahl technique, digestion being performed in the tubes. Results are expressed in $\mu \mathrm{g}$. bacterial nitrogen $/ 10 \mathrm{ml}$. medium to the nearest $10 \mu \mathrm{g}$. Each result is the mean of duplicate determinations.

Basal medium. This was essentially the same as that of Chattaway et al. (1949), with the addition of pteroylglutamic acid, thiamine and cobaltous chloride; hydroxyproline was absent. Since the exact amino acid requirements of the Dundee organism were not known, equal concentrations of each amino acid were used with the exception of glutamic acid (Mueller, 1940) and tyrosine (solubility considerations). Wherever possible synthetic amino acids were used. The basal medium was made up as required from the following stock solutions: (i) Amino acids (mg./l.); DL-alanine, 800; L-arginine, 400; DL-aspartic acid, 800; L-cystine, 400; DL-glutamic acid, 4000; glycine, 400; L-histidine, 400; DL-leucine, 800; L-isoleucine, 400; L-lysine, 400; DL-methionine, 800; DLphenylalanine, 800 ; L-proline, 400; DL-serine, 800 ; DL-threonine, 800; L-tryptophan, 400; L-tyrosine, 100; DL-valine, $800 ; \mathrm{KH}_{2} \mathrm{PO}_{4}, 2000 ; \mathrm{NaCl}, 4000$. (ii) Growth accessories (mg./l.); pyridoxine, 60; nicotinic acid, 20; calcium 
pantothenate, 10 ; riboflavin, 10 ; thiamine, $10 ; p$-aminobenzoic acid, 5 ; biotin, 0.1; pteroylglutamic acid, 0.1. (iii) Salts (mg./l.); $\mathrm{MgSO}_{4} .7 \mathrm{H}_{2} \mathrm{O}, 5 \times 10^{4}$; $\mathrm{CuSO}_{4} .5 \mathrm{H}_{2} \mathrm{O}, 100 ; \mathrm{ZnSO}_{4} .7 \mathrm{H}_{2} \mathrm{O}, 80 ; \mathrm{MnSO}_{4} .4 \mathrm{H}_{2} \mathrm{O}, 30 ; \mathrm{CoCl}_{2} .6 \mathrm{H}_{2} \mathrm{O}, 10 ;$ $\mathrm{FeNH}_{4}\left(\mathrm{SO}_{4}\right)_{2} \cdot 12 \mathrm{H}_{2} \mathrm{O}, 173$. (iv) $2 \mathrm{M}$-sodium lactate (from A.R. lactic acid), $400 \mathrm{ml} . / 1$.; $\mathrm{CaCl}_{2}, 1.0 \mathrm{~g} . / 1$.

The final basal medium was prepared by mixing $500 \mathrm{ml}$. (i), $5 \mathrm{ml}$. (ii), $5 \mathrm{ml}$. (iii), diluting, bringing the $\mathrm{pH}$ to $\mathbf{7 \cdot 6}$ and adjusting the volume to 11 . After dispensing and autoclaving the medium for $10 \mathrm{~min}$. at $10 \mathrm{lb} . / \mathrm{sq} . \mathrm{in} .0 .5 \mathrm{ml}$. of solution (iv) $/ 10 \mathrm{ml}$. of medium was added aseptically. Growth of Corynebacterium diphtheriue (Dundee) was never observed on this basal medium in the absence of the added growth factors under investigation.

Source of active factor. An ether-extracted fish-liver concentrate (Yellow Fin Liver Stick Concentrate, Van Camp Laboratories, U.S.A.) was used as a source of the active factor. Addition of $0.01 \mathrm{ml}$. of this concentrate to $5 \mathrm{ml}$. basal medium produced a good growth response and was used as a standard comparison.

Method of detecting purines on paper chromatograms. Before the apparatus for the ultraviolet photographic technique of Markham \& Smith (1949) was assembled an alternative method was sought. The method detailed below was finally adopted; because of its convenience and high sensitivity its use was continued in conjunction with the ultraviolet method.

The descending paper partition chromatographic technique of Consden, Gordon \& Martin (1944) was used. Whatman no. 54 paper $(18 \times 22$ in.) was selected because of its good wet strength and minimal final background colour. The chromatogram is developed with solvent, and after drying in a current of warm air is sprayed with $0 \cdot 1 \%(\mathrm{w} / \mathrm{v})$ copper acetate in ethanol, to which was added ascorbic acid $(1 \mathrm{mg} . / \mathrm{ml}$.) immediately before spraying. The chromatograms were air-dried, heated at $120^{\circ}$ for $5 \mathrm{~min}$. and washed in a rapid stream of tap water for about $30 \mathrm{~min}$. After drying, the paper was sprayed with $0.2 \%$ sodium diethyldithiocarbamate in a mixture of ethanol/water/ammonia sp.gr. $0.880,(50: 35: 15 ; \mathrm{v} / \mathrm{v} / \mathrm{v})$. The position of the purines was marked by dark brown spots on a straw-coloured background. Pyrimidines are not detected by this method; the sensitivity to purines was greater than with the technique of Markham \& Smith (1949).

Ultraviolet absorption data. These were obtained by means of a 'Unicam' S.P. 500 photoelectric quartz spectrophotometer.

\section{RESULTS}

The growth-promoting activity of purines

As a preliminary to fractionation of the active fish-liver concentrate an examination was undertaken of a variety of substances known to be required as nutrients by other organisms, but not previously tested for our organism. The following compounds were tested singly and in various mixtures at the concentrations indicated $(\mu \mathrm{g} . / \mathrm{ml}):. 10 \cdot 0$, adenine; $10 \cdot 0$, guanine; $10 \cdot 0$, xanthine; 10.0, hypoxanthine; $10 \cdot 0$, thymine; $10 \cdot 0$, cytosine; $10 \cdot 0$, uracil; $10 \cdot 0$, 
orotic acid; $10 \cdot 0$, guanosine; 100.0, glutamine; 100.0, inositol; $0 \cdot 1$, vitamin $\mathrm{B}_{12}$ (Cytamen); and $5 \times 10^{-4} \mathrm{ml}$. Tween 80 (oleic acid ester).

Hypoxanthine, adenine + guanine and adenine + xanthine permitted growth of the Dundee organism for the first time on a chemically defined medium. All the remaining compounds were entirely without activity. The extent of growth of all possible combinations of adenine, guanine, hypoxanthine and xanthine relative to hypoxanthine is shown in Table 1. Except with hypoxanthine, growth tests on the individual purines at concentrations in the range $1-100 \mu \mathrm{g} . / \mathrm{ml}$. showed no activity. The inhibitory effect of adenine, guanine and adenine + guanine on hypoxanthine activity is evident from Table 1. Xanthine appeared to aid in overcoming this inhibition and increased growth on the adenine+guanine mixture.

\section{Table 1. The relative activity of purines and purine mixiures}

These results are based on growth tests performed at a concentration of $10 \mu \mathrm{g}$. of each purine $/ 10 \mathrm{ml}$. basal medium. Incubation: $72 \mathrm{hr}$. at $37^{\circ}$.

\begin{tabular}{|c|c|c|c|}
\hline Purine added & $\begin{array}{c}\text { Relative } \\
\text { activity } \\
(\%)\end{array}$ & Purine added & $\begin{array}{c}\text { Relative } \\
\text { activity } \\
(\%)\end{array}$ \\
\hline Hypoxanthine (H) & 100 & $\mathbf{A}+\mathbf{X}$ & 1 \\
\hline Adenine (A) & o & $\mathbf{G}+\mathbf{X}$ & 0 \\
\hline Guanine (G) & $\mathbf{0}$ & $\mathbf{H}+\mathbf{A}+\mathbf{G}$ & 6 \\
\hline Xanthine (X) & 0 & $\mathbf{H}+\mathbf{A}+\mathbf{X}$ & 100 \\
\hline $\mathbf{H}+\mathbf{A}$ & 12 & $\mathrm{H}+\mathrm{G}+\mathrm{X}$ & 100 \\
\hline $\mathbf{H}+\mathbf{G}$ & 6 & $\mathbf{A}+\mathbf{G}+\mathbf{X}$ & 25 \\
\hline $\mathbf{H}+\mathbf{X}$ & 100 & $\mathbf{H}+\mathbf{A}+\mathbf{G}+\mathbf{X}$ & 100 \\
\hline $\mathbf{A}+\mathbf{G}$ & 6 & & \\
\hline
\end{tabular}

Apart from guanosine, no other nucleosides or nucleotides were available for testing. An electrophoretically purified sample of commercial ribonucleic acid (Yeast Nucleic Acid, sodium salt, British Drug Houses Ltd.; 2.5 mg./ml.) was used to prepare nucleotide, nucleoside and free purine fractions by modifications of the methods of Levene \& Bass (1931) as follows: (i) Nucleotides. $5 \mathrm{ml}$. sodium nucleate solution was sealed with $0.12 \mathrm{ml}$. ammonia solution (sp.gr. 0-880) and heated at $120^{\circ}$ for $30 \mathrm{~min}$. Ammonia was immediately removed by evaporation under reduced pressure and the volume made to $50 \mathrm{ml}$. with water. (ii) Nucleosides. $5 \mathrm{ml}$. sodium nucleate solution was sealed with $1 \mathrm{ml}$. aminonia solution (sp.gr. 0.880 ) and heated at $120^{\circ}$ for $3.5 \mathrm{hr}$. Subsequent treatment was as above for nucleotides. (iii) Free purine bases. $5 \mathrm{ml}$. sodium nucleate solution was mixed with $2 \mathrm{ml}$. $5 \mathrm{~N}$-hydrochloric acid and left overnight at room temperature. Hydrochloric acid was removed by evaporation under reduced pressure and finally over solid potassium hydroxide in vacuo. The final volume was $50 \mathrm{ml}$.

Activity tests revealed growth only when the fraction containing free purine bases was present; the nucleoside and nucleotide fractions were inactive. 


\section{The active material in fish-liver concentrate}

In view of the previously reported activity of ninhydrin-positive material (Chattaway et al. 1949), it was necessary to determine whether purines were the active agents in the fish-liver concentrate and, if so, whether they accounted for all of the activity. A modification of the copper-precipitation technique of Vendrely (1947) was applied to the concentrate before and after acid hydrolysis, so as to distinguish between free and bound purines. The modifications, designed to minimize the accumulation of salt which might interfere in subsequent growth experiments, were as follows: (i) replacement of the $30 \%$ sodium metabisulphite solution by water saturated with sulphur dioxide during the precipitation stage; (ii) decomposition of the copper-purine complex with hydrogen sulphide. No difference was observed in the final purine extracts prepared by either the unmodified or modified method.

Sixty $\mathrm{ml}$. of fish-liver concentrate diluted to $250 \mathrm{ml}$. with water were heated in a boiling-water bath with $30 \%$ by volume of a saturated solution of $\mathrm{SO}_{8}$ in distilled water; $10 \%(\mathrm{w} / \mathrm{v}) \mathrm{CuSO}_{4} .5 \mathrm{H}_{2} \mathrm{O}$ were added to the stirred solution in the ratio 5:4 until no further precipitation occurred. 'The precipitate was removed by centrifugation, washed twice with small volumes of distilled water and the washings added to the supernatant fluid which was reserved.

Precipitate. The precipitate was suspended in $20 \mathrm{ml}$. of water, heated to $100^{\circ}$ and hydrogen sulphide passed through the suspension for $15 \mathrm{~min}$. The supernatant fluid was preserved and the precipitate resuspended and again treated with hydrogen sulphide. After washing twice with distilled water, the precipitate was discarded and the combined supernatant fluids and washings were evaporated in vacuo. The $\mathrm{pH}$ value was adjusted to $7 \cdot 6$ and the solution made to a final volume of $60 \mathrm{ml}$. This solution was referred to as purine extract P1.

Supernatant fluid. The supernatant fluid from the above precipitation was heated at $100^{\circ}$ to remove sulphur dioxide, freed from copper by hydrogen sulphide and the copper sulphide discarded after repeated washing. The combined supernatant fluids and washings were freed of hydrogen sulphide, the $\mathrm{pH}$ value adjusted to $7 \cdot 6$ and the final volume made to $60 \mathrm{ml}$. A $30 \mathrm{ml}$. sample was preserved and designated S1. The remaining $30 \mathrm{ml}$. was made $\mathrm{N}$ with hydrochloric acid and heated at $100^{\circ}$ for $8 \mathrm{hr}$. in sealed tubes. The hydrolysate was repeatedly evaporated under reduced pressure to remove the hydrochloric acid and the precipitation process repeated, yielding an extract $\mathrm{P} 2$ and supernatant fluid material S2.

Fig. 1 shows the ultraviolet absorption spectra between 280 and $280 \mathrm{~m} \mu$. of P1 and P2 diluted 1:200 and 1:20, respectively. The curves indicated that the purine content of the fish-liver concentrate was present in the form of the free purine bases. No purines were detected chromatographically in $\mathbf{P 2}$ even in concentrated solutions.

Chromatographic examination of $\mathrm{PI}$ in a variety of solvents revealed the presence of large amounts of hypoxanthine, lesser amounts of xanthine, and traces of adenine and guanme which were only discernible in highly concentrated solutions. Reprecipitation of $\mathrm{Pl}$ was necessary to remove traces of 
ninhydrin-positive material and a copper-reacting spot not corresponding to any of the four purines previously mentioned. This latter is considered in the next section.

\section{Isolation of hypoxanthine and xanthine from $P 1$}

To obtain further evidence that hypoxanthine and xanthine were the major purine constituents of the fish-liver concentrate, a chromatographic separation was performed as follows. Thirty $\mathrm{ml}$. of $\mathrm{Pl}$ solution (once-precipitated) was evaporated to dryness, dissolved in $3 \mathrm{ml}$. water and distributed across $18 \times$ 22 in. sheets of Whatman no. 54 paper in $10 \mu \mathrm{l}$. spots. The chromatograms were developed with $n$-butanol/diethylene glycol/water $(4: 1: 1)$ in an atmosphere of

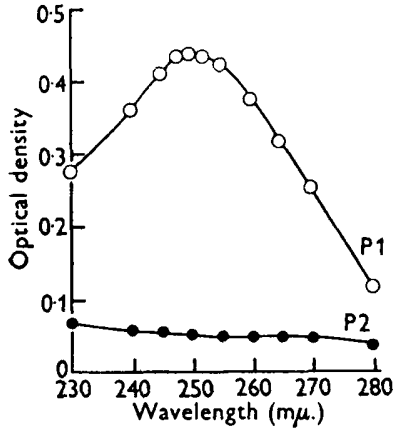

Fig. 1

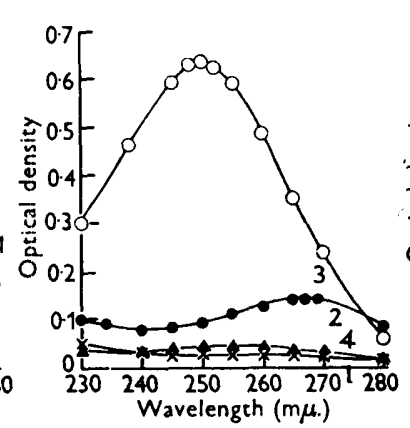

Fig. 2

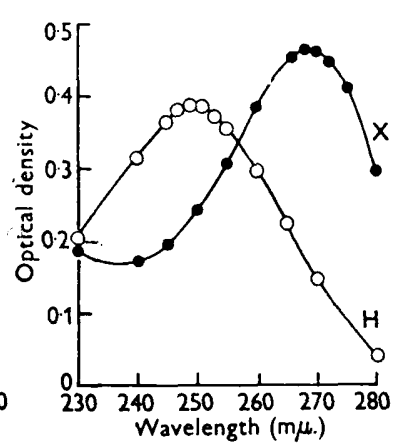

Fig. 3

Fig. 1. The ultraviolet absorption spectra of purine extracts prepared from fish-liver concentrate before (P1), and after (P2), acid hydrolysis. Dilution: P1, 1:200; P2, 1:20. Solvent: water. $\mathrm{pH}=$ c. 7:0. Quartz cells, $1 \mathrm{~cm}$. light path.

Fig. 2. The ultraviolet absorption spectra of the copper-positive spots in the purine extract (P1) separated chromatographically. Dilution: $1: 100$. Solvent: water. $\mathrm{pH}=c .7 \cdot 0$. Quartz cells, $1 \mathrm{~cm}$. light path. $1-4=$ fractions $1-4$.

Fig. 3. The ultraviolet absorption spectra of xanthine $(\mathrm{X})$ and hypoxanthine $(\mathrm{H})$. Concentration $=7 \mu \mathrm{g} . / \mathrm{ml}$. Solvent: water. $\mathbf{p H}=$ c. $7 \cdot 0$. Quartz cells, $1 \mathrm{~cm}$. light path.

ammonia (Vischer \& Chargaff, 1948), and marker strips were cut from each edge and developed by the copper method. Four transverse strips were then cut corresponding to four copper-positive spots on the marker strips and each was macerated and eluted by shaking with three successive $100 \mathrm{ml}$. volumes of dilute ammonia (1 ml. sp.gr. 0.880 ammonia solution to $99 \mathrm{ml}$. water). The combined eluates from each strip were concentrated to their original volume. Repetition of the chromatography of the four fractions in the same solvent revealed that fraction 1 corresponded to the unidentified, slow-moving material mentioned earlier as being absent from reprecipitated samples of $\mathbf{P 1}$; fraction 2 to the xanthine and guanine markers; fractions 3 and 4 to the hypoxanthine and adenine markers respectively. The absorption spectra of the four fractions diluted 1:100 with water is shown in Fig. 2. The well-defined peaks of fractions 2 and 3 at 267 and $250 \mathrm{~m} \mu$., respectively, closely correspond to the peaks shown by neutral $(\mathrm{pH} 7 \cdot 0)$ aqueous solutions of xanthine and hypoxanthine as determined experimentally (Fig. 3) and to the data of Hotchkiss 


\section{Growth factors for C. diphtheriae strain Dundee}

(1948). The absence of a well-defined peak in fraction 4 is consistent with the small adenine content of $\mathbf{P} 1$, as observed chromatographically. The same argument cannot be applied to fraction 1 since, unlike adenine, a relatively high concentration of the material could be detected on chromatograms and would have been expected to absorb strongly if it were purine. The fact that the material was absent after reprecipitation of the purine extract and could also be detected in large amounts in the fish-liver concentrate, before and after copper precipitation, suggests that its presence was a result of co-precipitation with the purines.

The concentrations of xanthine and hypoxanthine in fractions 2 and 3 , respectively, were 220 and $1140 \mu \mathrm{g} . / \mathrm{ml}$. These results are based on standard curves for pure samples of purines measured at the wavelength of maximum absorption and are confirmed by calculation from the absorption data of Hotchkiss (1948).

\section{Comparison of growth on fish-liver concentrate, purine extract and purines}

A comparison of the growth promoted by the fish-liver concentrate, reprecipitated purine extract $P 1$, hypoxanthine + xanthine and hypoxanthine at comparable levels is presented in Table 2. Growth on the fish-liver concentrate exceeded that on the purine extract, hypoxanthine + xanthine or hypoxanthine

\section{Table 2. Comparison of growth on fish concentrate, purine extract and purines}

Iypoxanthine + xanthine, and hypoxanthine, were tested at concentrations equivalent to those present in purine extract and fish-liver concentrate, e.g. $0.01 \mathrm{ml}$. fish-liver concentrate $\equiv 0.01 \mathrm{ml}$. purine extract $\equiv c$. ig. hypoxanthine $+c$. $2 \cdot 5 \mu \mathrm{g}$. xanthine $\equiv c$. $10 \mu \mathrm{g}$. hypoxanthine. Incubation: $144 \mathrm{hr}$. at $37^{\circ}$. Bacterial ogen values are average of duplicates to nearest $10 \mu \mathrm{g}$.

Material added to basal medium

\begin{tabular}{|c|c|c|c|c|c|c|c|}
\hline \multirow[t]{2}{*}{$\begin{array}{l}\text { Iditions } \\
\text { nl./ml. } \\
\text { edium) }\end{array}$} & $\begin{array}{l}\text { Fish-liver } \\
\text { concentrate }\end{array}$ & $\begin{array}{l}\text { Purine } \\
\text { extract }\end{array}$ & $\begin{array}{c}\text { Hypo- } \\
\text { xanthine } \\
\text { + xanthine }\end{array}$ & $\begin{array}{c}\text { Hypo- } \\
\text { xanthine }\end{array}$ & $\begin{array}{c}\text { Purine } \\
\text { extract }+ \\
\text { supernatant }\end{array}$ & $\begin{array}{c}\text { Hypo- } \\
\text { xanthine }+ \\
\text { xanthine }+ \\
\text { supernatant }\end{array}$ & Superna \\
\hline & \multicolumn{7}{|c|}{ Amount of growth ( $\mu \mathrm{g}$. bacterial-N/10 ml. medium) } \\
\hline$\times 10^{-5}$ & $\mathbf{0}$ & $\mathbf{0}$ & $\mathbf{0}$ & $\mathbf{0}$ & - & 一 & - \\
\hline$\times 10^{-4}$ & 20 & 20 & 20 & - & - & 一 & - \\
\hline$\times 10^{-8}$ & 70 & $\mathbf{5 0}$ & $\mathbf{3 0}$ & $\mathbf{8 0}$ & 40 & 20 & $\mathbf{0}$ \\
\hline$\times 10^{-8}$ & 380 & 170 & 150 & 110 & - & - & $\mathbf{5 0}$ \\
\hline$\times 10^{-2}$ & 610 & 170 & 170 & 280 & - & - & - \\
\hline
\end{tabular}

alone. The activity of the mixture of hypoxanthine + xanthine closely paralleled that of the purine extract. The growth observed at the higher level of the supernatant $\mathbf{S} 1$ was probably due to traces of purines not precipitated. Upon recombination of the purine extract $\mathbf{P} 1$ and the supernatant fluid material $\mathbf{S} 1$ it was not possible to reproduce growth on the whole fish-liver concentrate. Thus those growth-stimulating factors responsible for the increased growth on the original fish-liver concentrate above that of the purine extract must have been either lost or destroyed during the precipitation procedure. 
Apparently the difference was not due to the presence of inhibitory material added during purine precipitation, since growth on $\mathrm{P} 1+\mathrm{S} 1$ was approximately the same as growth on P1 alone.

\section{DISCUSSION}

The addition of purines to a chemically defined medium almost identical with that of Chattaway et al. (1949) has thus been shown to allow the growth of Corynebacterium diphtheriae strain Dundee. Also, the growth-initiating activity (as distinct from any further growth-stimulatory effect) of a fish-liver concentrate has been correlated with its purine content. These findings differ considerably from the activity of ninhydrin-positive material found by Chattaway et al. (1949). One explanation might be that purines and the ninhydrin-positive material are interchangeably active. No evidence in this respect has been obtained in preliminary experiments designed to find a pure protein source of active peptides. An alternative suggestion is that the activity of the material of Chattaway et al. was due to the presence of purines. However, comparison of $R_{F}$ data reveals no such correlation. Possibly the most plausible explanation is to postulate the presence in the material of Chattaway et al. of material involved in the synthesis of purines. Chattaway et al. reported different properties of the growth-factor preparations from liver and yeast. Their yeast extract was active at concentrations as low as $1.7 \times 10^{-4} \mu \mathrm{g} . / \mathrm{ml}$.; the present investigation has shown purine activity only as low as $0 \cdot 1 \mu \mathrm{g} . / \mathrm{ml}$. This difference, by a factor of $10^{4}$, suggests some fundamental difference in function. Whatever the correct explanation may be, it is apparent that the fish-liver concentrate contains some additional material which, whilst having no ability to promote growth in the absence of purines, supplements growth in their presence. Apparently, a requirement for purines has not previously been reported for any other strain of $C$. diphtheriae; an examination of the other gravis strains reported to need the Dundee factor might reveal similar requirements.

It now seems fairly certain that $p$-aminobenzoic acid $(p$-AB) and the folic acid group of factors, in the form of a coenzyme, are concerned in the biological synthesis of purines. It has been suggested (Shive et al. 1947) that the coenzyme is responsible for the condensation of a 'one-carbon unit' with 4amino-5-imidazolecarboxamide, or more probably a derivative of it (Shive, 1950; Woods, 1952), to produce the purine nucleus. Since $p$-AB and pteroylglutamic acid were present in the medium throughout the present work, the purine requirement found may have been due to an inabiiity to complete the synthesis of this coenzyme.

Pennington (1942) found that either hypoxantnine or adenine + guanine was required for the growth of Spirillum serpens on a basal medium of asparagine + salts. Inhibition of hypoxanthine activity by adenine or guanine was also reported. Thus, whilst it has been pointed out (Brown, 1953) that a wide range of interconvertibility of adenine and guanine by micro-organisms exists, $S$. serpens and Corynebacterium diphtheriae strain Dundee appear to be unique in having an absolute requirement for both under certain conditions.

In Escherichia coli it seems probable that purine synthesis proceeds by way 
of the ribotide of 4-amino-5-imidazolecarboxamide (Greenberg, 1952). In yeast (Williams \& Buchanan, 1953) and pigeon liver (Buchanan \& Schulman, 1953) this ribotide is converted to inosinic acid. Results with mutant strains of Aerobacter aerogenes (Magasanik \& Brooke, 1954) suggest that guanine is produced from inosinic acid via a xanthine derivative which is not xanthosine, but is possibly a ribotide of xanthine. In the present study strong growth was observed on hypoxanthine alone, which suggests a facile conversion into nucleic acid adenine and guanine. This might proceed either by direct conversion into adenine or guanine and subsequent incorporation into nucleic acid, or by a preliminary conversion into a hypoxanthine derivative followed by conversion into the corresponding adenine and guanine derivatives. The present results favour the latter alternative because of the lower growth on adenine + guanine, and agrees with the suggestion of other workers that interconversion probably proceeds via the derivatives. Growth on adenine+ xanthine was very slow, but does suggest a slight ability for interconversion between xanthine and guanine. In general, the results indicate a similarity in metabolic pathway to that found with $\boldsymbol{A}$. aerogenes (Magasanik \& Brooke, 1954). The question of whether the purine derivatives are ribosides or ribotides can only be answered by testing the pure compounds. However, the experiments with hydrolysed ribonucleic acid indicate that ribose derivatives of adenine and guanine are not involved.

We wish to express our thanks to Professor F. C. Happoid for his interest and encouragement throughout the work and in the preparation of this paper. We are also indebted to $\mathrm{Mr}$ T. J. Bowen for the preparation of the electrophoretically purified sample of ribonucleic acid.

\section{REFERENCES}

Brown, G. D. (1953). Nucleic acids, purines and pyrimidines. Ann. Rev. Biochem. 22, 141.

Buchanan, J. M. \& Schulman, M. P. (1953). Biosynthesis of the purines. III. Reactions of formate and inosinic acid and an effect of the citrovorum factor. J. biol. Chem. 202, 241.

Chattaway, F. W., Happold, F. C. \& Sandford, M. (1944). A growth factor for C. diphtheriae present in liver. Biochem. J. 38, 111.

Chattaway, F. W., Dolby, D. E., Hald, D. A. \& Happold, F. C. (1949). Growth factors for Corynebacterium diphtheriae. Biochem. J. 45, 592.

Consden, R., Gordon, A. H. \& Martin, A. J. P. (1944). Qualitative analysis of proteins: a partition chromatographic method using paper. Biochem. J. 38, 224.

Evans, W. C., Handley, W. R. C. \& Happold, F. C. (1939). The nutrition of C. diphtheriae. Pantothenic acid as an essential growth factor for ceriain strains of C. diphtheriae gravis: the synthesis of some physiologically active compounds by $C$. diphtheriae cultures in synthetic media. Brit. J. exp. Path. 20, 396.

Greenberg, G. R. (1952). Isolation of 4-amino-5-imidazolecarboxamide riboside from the culture medium of sulphonamide-inhibited Escherichia coli. J. Amer. chem. Soc. 74, 6307.

Hотснкiss, R. D. (1948). The quantitative separation of purines, pyrimidines and nucleosides by paper chromatography. J. biol. Chem. 175, 315.

Levene, P. A. \& Bass, L. W. (1931). Nucleic Acids. New York: The Chemicai Catalog Company. 
Magasanik, B. \& Brooke, M. S. (1954). The accumulation of xanthosine by a guanineless mutant of Aerobacter aerogenes. J. biol. Chem. 206, 83.

Markham, R. \& Smith, J. D. (1949). Chromatographic studies of nucleic acids. 1. A technique for the identification and estimation of purine and pyrimidine bases, nucleosides and related substances. Biochem. J. 45, 294.

Mueller, J. H. (1937 a). Studies on cultural requirements of bacteria. X. Pimelic acid as a growth stimulant for $C$. diphtheriae. J. Bact. 34, 163.

Mueller, J. H. (1937b). Nicotinic acid as a growth accessory substance for the diphtheria bacillus. $J$. Bact. 34, 429.

Mueller, J. H. (1940). Nutrition of the diphtheria bacillus. Bact. Rev. 4, 97.

Mueller, J. H., Klise, K. S., Porter, E. F. \& Graybiel, A. (1933). Siudies on cultural requirements of bacteria. III. The diphtheria bacillus. J. Bact. 25, 509.

Mueller, J. H. \& Klotz, A. W. (1938). Pantothenic acid as a growth factor for the diphtheria bacillus. J. Amer. chem. Soc. 60, 3086.

Mueller, J. H. \& Subbarow, Y. (1937). Studies on cultural requirements of bacteria. IX. Tissue extractives in the growth of the diphtheria bacillus. J. Bact. 34, 153.

Pappenheimer, A. M., JUn. (1936). Studies in diphtheria toxin production. II. Production of potent diphtheria toxin in a simple amino-acid medium. Brit. $J$. exp. Path. 17, 342.

Pappenheimer, A. M., Jun., \& Johnson, S. J. (1936). Studies in diphtheria toxin production. I. The effect of iron and copper. Brit. J. exp. Path. 17, 335.

Pennington, D. E. (1942). Purines as growth requirements of Spirillum serpens. Proc. nat. Acad. Sci., Wash. 28, 272.

ShIve, W. (1950). The utilization of antimetabolites in the study of biochemical processes in living organisms. Ann. N.Y. Acad. Sci. 52, 1212.

Shive, W., Ackermann, W. W., Gordon, M., Getzendaner, M. E. \& Eakin, R. E. (1947). 5(4)-Amino-4(5) imidazolecarboxamide, a precursor of purines. J. Amer. chem. Soc. 69, 725.

VeNDRELy, R. (1947). Sur la détermination de quantités d'azote purique de l'ordre de 10 à 40 gammas. Application aux acides nucléiques, nucléoprotéides, tissus, microorganismes. Biochim. biophys. Acta, $1,95$.

Vischer, E. \& ChargafF, E. (1948). The separation and quantitative estimation of purines and pyrimidines in minute amounts. J. biol. Chem. 176, 703.

Williams, W. J. \& Buchanan, J. M. (1953). Biosynthesis of the purines. IV. The metabolism of 4-amino-5-imidazole-carboxamide in yeast. J. biol. Chem. 202, 253.

Woods, D. D. (1952). Vitamin-B-group substances, especially folic acid and $B_{12}$, in the metabolism of microorganisms. Bull. World Hlth Org. 6, 35. 